\title{
Deployment of Electric Induction Technologies into Cooktops Plates as a Part of Energy Sustainability
}

\author{
Alberto Tama \\ International University Center of Barcelona (UNIBA), University of Barcelona, Barcelona, Spain \\ Email: atama@espol.edu.ec
}

How to cite this paper: Tama, A. (2022) Deployment of Electric Induction Technologies into Cooktops Plates as a Part of Energy Sustainability. Smart Grid and Renewable Energy, 13, 55-74.

https://doi.org/10.4236/sgre.2022.133004

Received: January 24, 2022

Accepted: March 6, 2022

Published: March 9, 2022

Copyright $\odot 2022$ by author(s) and Scientific Research Publishing Inc. This work is licensed under the Creative Commons Attribution International License (CC BY 4.0).

http://creativecommons.org/licenses/by/4.0/

\section{(c) (i) Open Access}

\begin{abstract}
For a long time now, humanity has been facing the phenomenon known as "climate change", a major challenge of which we must be aware of what we are doing so as not to affect ourselves or future generations. It is evident that, if what is sought is a sustainable energy future, the current energy model implemented in certain countries and regions of the world is not the most adequate and makes the achievement of this goal unfeasible. This situation threatens to greatly alter our ecosystems and our social structures, and one of the key actions to mitigate it is, undeniably, the generalization of the use of renewable energy sources; and specifically, the non-conventional sources, referring to solar and wind, technologies that comply with the principle of energy complementarity; however, there are other possible solutions such as the deployment of programs that consider efficient cooking technologies; involving with it is everything related to energy security and equity, as well as environmental protection. In this article, as a technology to be considered to reduce and mitigate the Greenhouse Gases (GHG) emissions, an analysis of the efficiency assessment of electric induction cooktops and the determination of their potential energy savings are carried out. The impact of these results is taken into consideration and a series of conclusions and recommendations for improvement are issued.
\end{abstract}

\section{Keywords}

Energy Sustainability, Sustainable Development, Clean Cooking, Efficient Cooking, Sustainable Development Goals, Energy Savings, Electric Induction Cooktop

\section{Introduction}

"The development of cleaner and more efficient energy technologies and the use 
of renewable energy sources will play an important role in the sustainable development of a future energy strategy. The promotion of renewable energy sources and the development of cleaner and more efficient energy systems are of high priority for security and diversification of energy supply, protection of the environment and social and economic cohesion" [1].

The world as we know it, and since its beginnings, has faced-in short-4 waves, as shown in Figure 1, the first, known as Social Unevenness, which occurred at the local, regional and even global levels; the second one, as a consequence of the industrial revolution, called the Climate Change Momentum; the third one, and as in any system with crests, there are also the so-called valleys in this case, called the Economic Recession; and finally, the last wave, by which we have been impacted worldwide and simultaneously, is known as the COVID-19 pandemic. The recovery from the consequences of this last wave will not be easy; however, transformation is still possible, bearing in mind that there is an inseparable relationship between development, climate and energy, remembering that without energy we could not have the technology.

In order to curb the COVID-19 contagion, countries worldwide implemented confinement measures, this led to the interruption of economic activities, simultaneously causing a significant temporary reduction in $\mathrm{CO}_{2}$ emissions, which was expected to be close to the reduction that the world would have to make each year to achieve the temperature increase target of the Paris Agreement. This situation has served to make us realize that meeting the goal of avoiding a global average temperature increase above $1.5^{\circ} \mathrm{C}$ would imply important changes for society, and establish what is known as an era change.

Excessive emissions of $\mathrm{CO}_{2}$, which is a colorless, odorless gas composed of oxygen and carbon, are one of the main causes of global warming, a problem caused by human activity and aggravated by the long persistence of this gas in the atmosphere. The burning of fossil fuels for energy production, transportation and industry has been increasing to such an extent that the concentration of carbon dioxide in the atmosphere, measured at NOAA's Mauna Loa Atmospheric Baseline Observatory, reached a monthly average of 419.13 parts per million (ppm) in May 2021, the highest level since accurate measurements began 63 years ago [3].

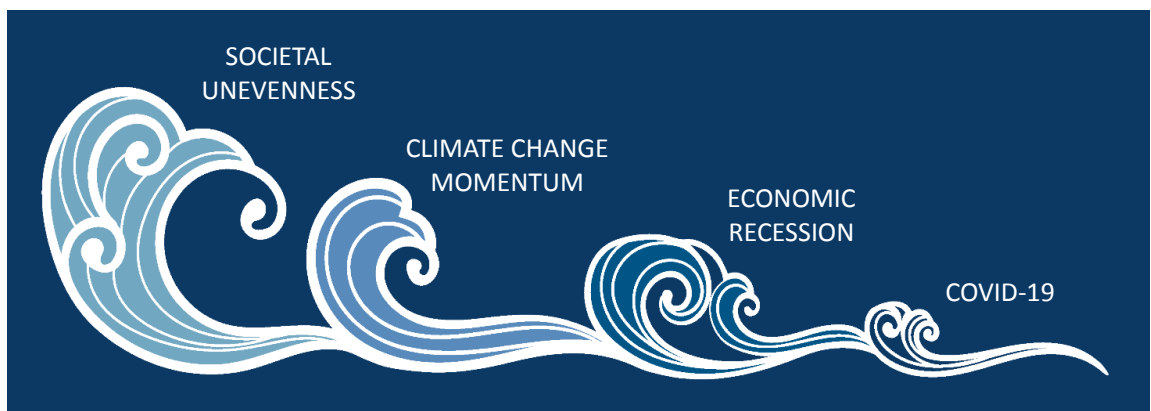

Figure 1. The waves through which humanity has faced. Source: World Energy Council [2]. 
The daily record of the referred concentration is maintained by the Scripps Institution of Oceanography of the University of California at San Diego and represented in the Keeling curve [4], as shown in Figure 2, which allows visualizing the existence of a clear correlation between the increase in atmospheric $\mathrm{CO}_{2}$ concentrations and the industrialization process.

Due to the COVID-19 pandemic, global $\mathrm{CO}_{2}$ emissions declined by approximately $5.4 \%$ in 2020; this event is considered the largest decline in history and is 4.5 times larger than that caused by the global financial crisis in 2009, as shown in Figure 3. Carbon dioxide emissions declined more than energy demand in 2020 because the pandemic affected oil and coal demand more than other energy sources, while renewable energy increased.

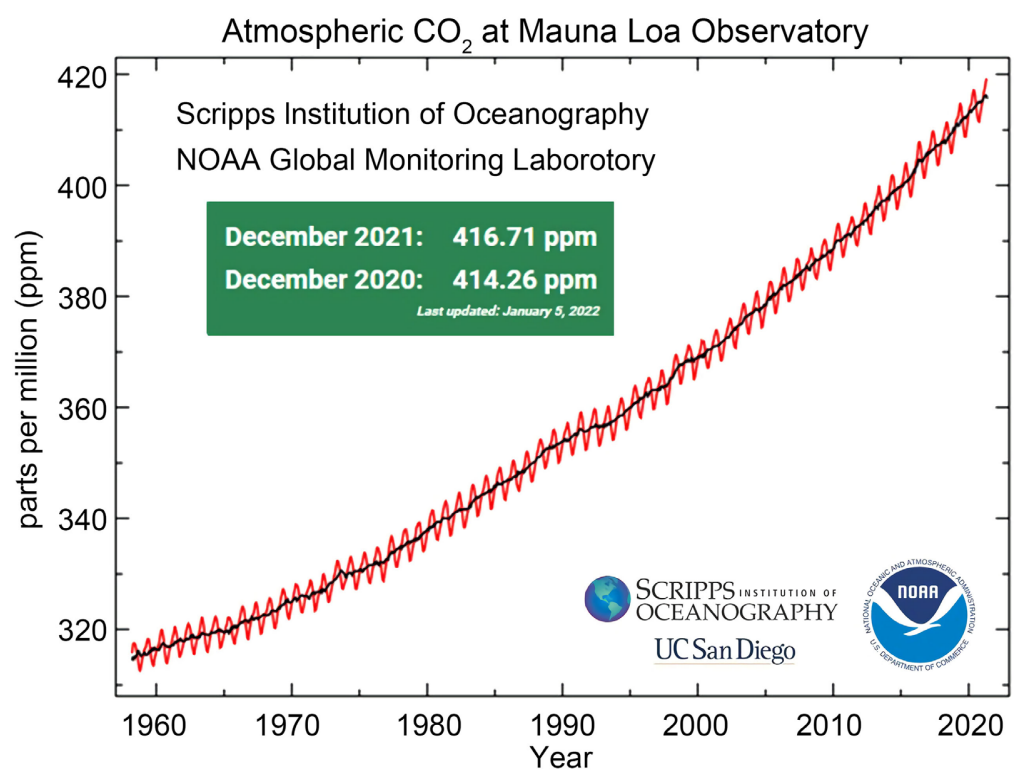

Figure 2. Evolution of carbon dioxide $\left(\mathrm{CO}_{2}\right)$ concentration levels in the atmosphere. Source: NOAA and Scripps Institution of Oceanography [3] [4] [5].

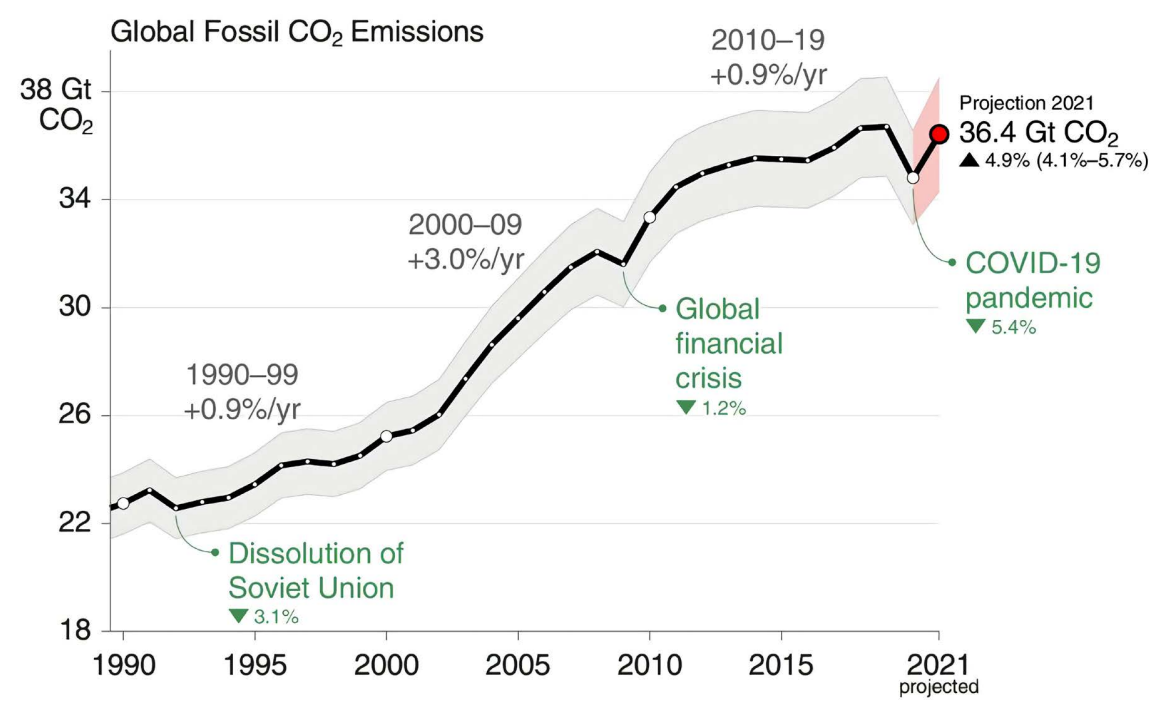

Figure 3. Global annual carbon dioxide $\left(\mathrm{CO}_{2}\right)$ emissions. Source: Global Carbon Project [6]. 
In 2021, the leading emitters of carbon dioxide were China, the United States, the EU 27, India, Russia and Japan. Together they account for just over two-thirds of total global $\mathrm{CO}_{2}$ emissions; where the Global Carbon Budget 2021, prepared by Carbon Brief, reveals that, in 2021, both China and India exceeded their 2019 emissions peaks. For their part, Chinese emissions grew by $5.5 \%$ between 2019 and 2021, while Indian emissions grew by $4.4 \%$, as shown in Figure 4 and Table 1 , and it can be concluded that global $\mathrm{CO}_{2}$ emissions have remained stable-if not declined slightly-over the past 10 years. In terms of percentage increase in carbon dioxide emissions, 2021 has been led by India, since, according to the Global Carbon Project, the growth of its emissions is $12.6 \%$, which is $2.7 \mathrm{Gt}$ of $\mathrm{CO}_{2}$. For its part, China, the world's largest emitter, released into the atmosphere, about $11 \mathrm{Gt}$ of $\mathrm{CO}_{2}, 4 \%$ more than in 2020 .

Table 1. Summary of fossil $\mathrm{CO}_{2}$ emissions in 2020 and 2021. Source: Global Carbon Project 2021 [7].

\begin{tabular}{ccccc}
\hline Region/Country & $\begin{array}{c}2020 \\
\text { emissions } \\
\left(\mathrm{Gt} \mathrm{CO}_{2} / \mathrm{yr} .\right)\end{array}$ & $\begin{array}{c}2020 \\
\text { growth } \\
\text { (percent) }\end{array}$ & $\begin{array}{c}\text { 2021 projected } \\
\text { emissions growth } \\
\text { (percent) }\end{array}$ & $\begin{array}{c}\text { 2021 projected } \\
\text { emissions } \\
\left(\mathrm{Gt} \mathrm{CO}_{2} / \mathrm{yr} \text { ) }\right.\end{array}$ \\
\hline China & 10.7 & $1.4 \%$ & $4.0 \%$ & 11.1 \\
USA & 4.7 & $-10.6 \%$ & $7.6 \%$ & 5.1 \\
EU 27 & 2.6 & $-10.9 \%$ & $7.6 \%$ & 2.8 \\
India & 2.4 & $-7.3 \%$ & $12.6 \%$ & 2.7 \\
All others (incl. IAS $\left.{ }^{\mathrm{a}}\right)$ & 14.4 & $-7.0 \%$ & $2.9 \%$ & 14.8 \\
World (incl. IAS $\left.{ }^{\mathrm{a}}\right)$ & 34.8 & $-5.4 \%$ & $4.9 \%$ & 36.4 \\
\hline
\end{tabular}

${ }^{a}$ IAS: Emissions from use of international aviation and maritime shipping bunker fuels.

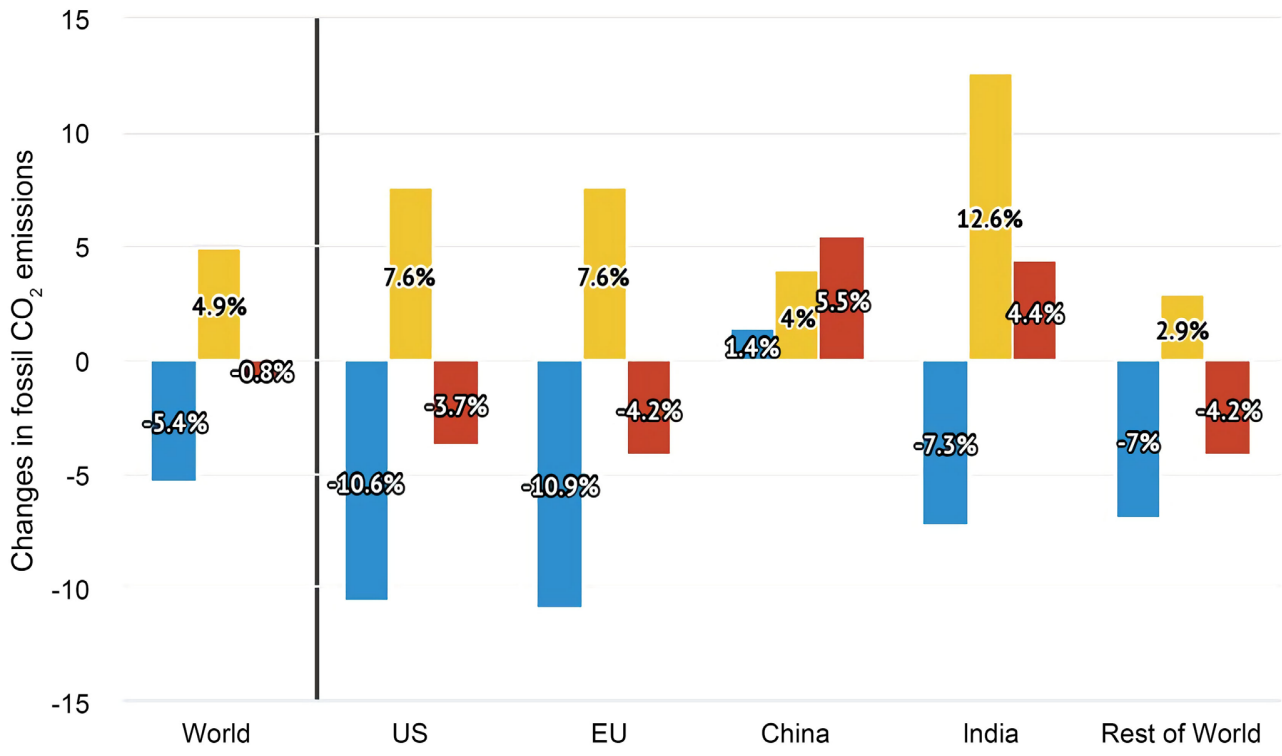

Figure 4. Changes in global emissions from 2019 to 2020 and 2019 to 2021 . Source: Carbon Brief. 
In $2010,57 \%$ of the world's population used clean fuels and technologies for cooking, rising to $66 \%$ in 2019 . The lethal combination of pandemic and confinement may result in slowing global progress, especially in resource-limited countries and regions. Thus, if no action is taken, one-third of the world's population will still be without clean cooking fuels and technologies by 2030, leading to significant adverse health effects and environmental degradation. The main goal of this study is to analyze the assessment of the efficiency of induction cookstoves and the determination of their energy-saving potential, as well as their influence on the energy trilemma [8]. The purpose is to encourage the energy control and regulation entities of the countries or regions that are interested in this proposal, to make the corresponding decisions for the implementation and deployment of an efficient cooking program as a support to energy sustainability.

\section{Sustainable Development}

"Sustainable Development (SD) responds to the needs of the present moment without jeopardizing or compromising the ability of future generations to meet their own needs" [1] [9]. From the energy point of view, sustainable development is only possible if the energy system is also sustainable, and the latter must be based on renewable energies and policies that promote energy efficiency and savings. As shown in Figure 5, there are three independent and mutually reinforcing components of the SD: economic development (Economy), social development (Society) and environmental protection (Biosphere).

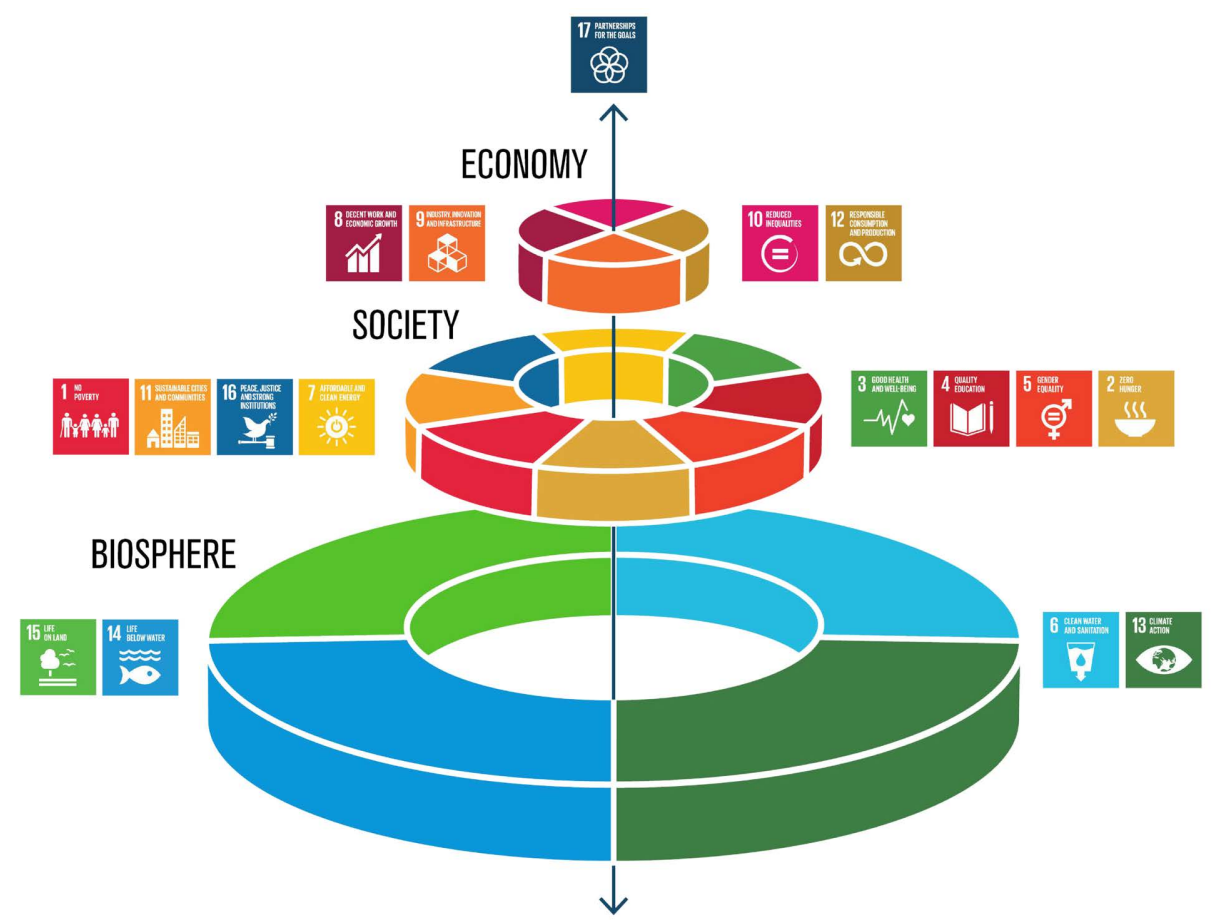

Figure 5. The Stockholm Resilience Centre’s SDGs “wedding cake”. Credit: Azote for Stockholm Resilience Centre, Stockholm University (CC BY 4.0) [10]. 
If what is required is to understand the meaning of Sustainability and its importance, the best way is through 17 Sustainable Development Goals (SDGs) that are part of the 2030 Agenda, developed at the 2015 Sustainable Development Summit. The SDGs aim to expand the Millennium Development Goals (MDGs) and achieve those goals that were not met. The central idea is that all countries, regardless of their level of development or wealth, commit to promoting prosperity and protecting the environment. The Sustainable Development Goals are not mandatory, but each country assumes the responsibility to work towards their fulfillment.

Undoubtedly, the key challenges of the 21 st century are monitoring and mitigating climate change and adapting to it. At the heart of this struggle, both from a social and industrial point of view, is energy as a protagonist, as a central element of progress, development and growth of our societies and our economy. However, this same element, which is fundamental for development, is also the main cause of emissions and, therefore, of climate change. While access to energy is relevant, it is central to poverty eradication, reduction of infant mortality, improvement of health, education, and promotion of gender equity among others; it is therefore clear that without universal access to modern energy services, the SDGs cannot be achieved. Figure 6 shows the set of necessary actions, proposed by the International Atomic Energy Agency (IAEA), to facing climate change, identified as one of the greatest environmental challenges affecting the planet

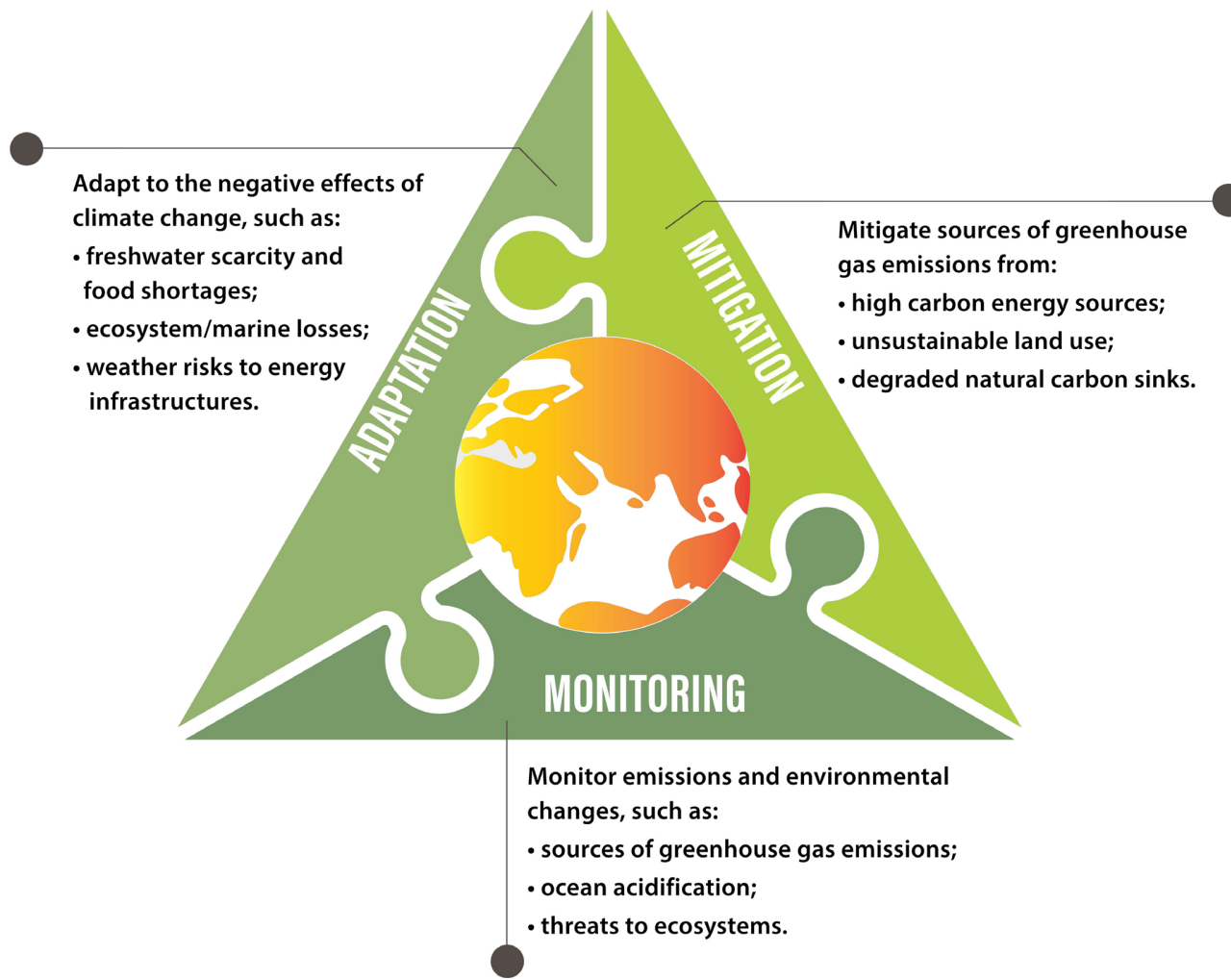

Figure 6. Triangle with roadmap and actions to be taken in order to combat climate change. Source: International Atomic Energy Agency-IAEA [11]. 
and humanity. In short, these key challenges correspond to the fundamental principle of resilience.

\section{Energy Trilemma}

Energy efficiency, renewable energies and energy savings are not isolated activities, as they were seen some years ago; nowadays these three concepts are integrated and enhanced through new trends such as electromobility, district heating, efficient cooking, distributed generation, storing or cogeneration and sustainable construction, to mention just a few. It is this comprehensive vision that we refer to when we talk about energy sustainability. Figure 7 summarizes this schematically.

The World Energy Council (WEC) has been working on what it denominates as Energy Sustainability, which it defines as the balance that exists between three dimensions, referring to: energy security, energy equity (taken as access to energy and its affordability; i.e., that energy is cheap) and mitigation of the environmental impact in energy production; i.e., environmental sustainability. This is what defines the energy trilemma, a choice between three options, which are (or appear to be) contradictory to each other. Thus, in order to build a strong basis for prosperity and competitiveness, individual countries must balance these three dimensions, as shown as Figure 8.

\section{The Electric Induction Cooktop}

To understand how an electric induction cooktop works [12], it is necessary to briefly recall the phenomenon of magnetic induction. The experiments of the English physicist and chemist Michael Faraday (1791-1867) in England in 1831 and those carried out independently by Joseph Henry in the United States in the same year, showed that it is possible to induce an electromotive force (emf-induced voltage) in a circuit, using a variable magnetic field. The results of this experimental evidence served as the basis for the enunciation of a basic and very important law of electro-magnetism known as Faraday's Law of Induction [13].
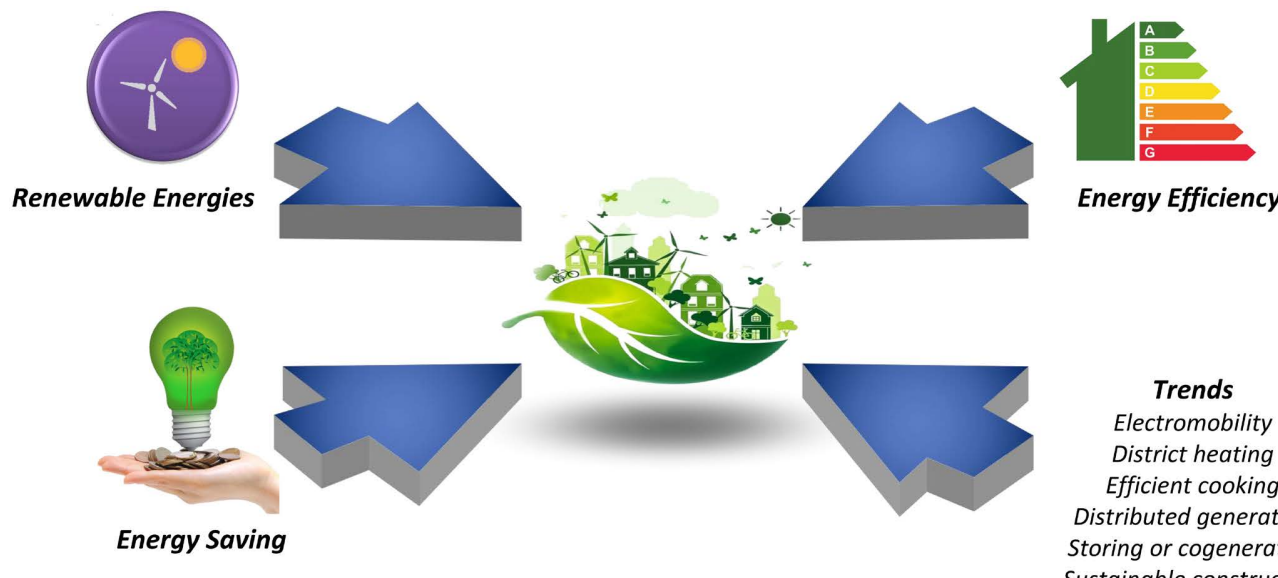

Energy Efficiency

Trends

Electromobility District heating Efficient cooking Distributed generation Storing or cogeneration Sustainable construction

Figure 7. Energy sustainability composition scheme. 

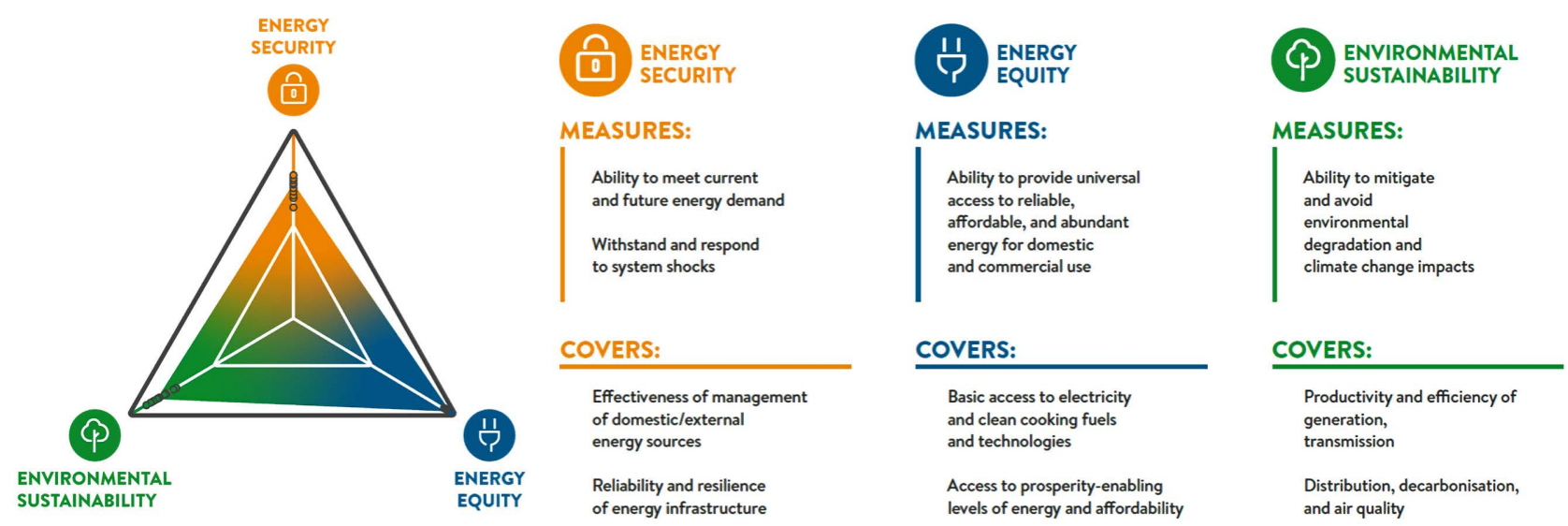

Figure 8. Trilemma index dimensions. Source: World Energy Council (WEC) [8].

Consequently, if an electric current of varying frequency generates a magnetic field, this varying magnetic field induces an electric current in a closed circuit; the latter, in turn, is related to a non-conservative electric field. The induction stove is a type of vitro-ceramic stove; and in essence, under the cooking zone-the main element-there is a flat copper coil with a spiral shape (Figure 9), through which an electric current of variable frequency $(20-100 \mathrm{kHz})$ is passed, which generates alternating magnetic fluxes. This current, therefore, produces a magnetic flux density with the same frequency with which the current in the coil varies, whose vector relation is indicated in expression (1) [14] [15].

$$
\boldsymbol{B}(P)=\sum_{i=1}^{N} \frac{\mu_{0} I(a i)^{2}}{2 N^{2}\left[h^{2}+\left(\frac{a i}{N}\right)^{2}\right]^{3 / 2}} \boldsymbol{\mu}_{z}
$$

where:

$a$ is the radius of the flat, spiral-shaped copper coil;

$h$ is the height above the coil at which the magnetic flux density is being determined;

$N$ is the number of turns of the coil, assuming that they are uniformly distributed and that each turn is a perfect circular spiral;

$i$ is the perfect circular loop element.

Note: a small computer program may be used if the number of turns $N$ is large.

This magnetic field does not cause any interaction if no electrical conductor is present. The containers (pots, pans, frying pans, casseroles, bowls, etc.) used in induction hobs must be made of metallic materials that have the following properties: 1) excellent electrical conductivity, ensuring that the electrical resistance of the container is very small, which allows the internal circulation of the so-called induced currents; and 2) ferromagnetic, in order to take advantage of magnetic hysteresis, which is the property of these materials to present opposition to the change in magnetic flux density. 


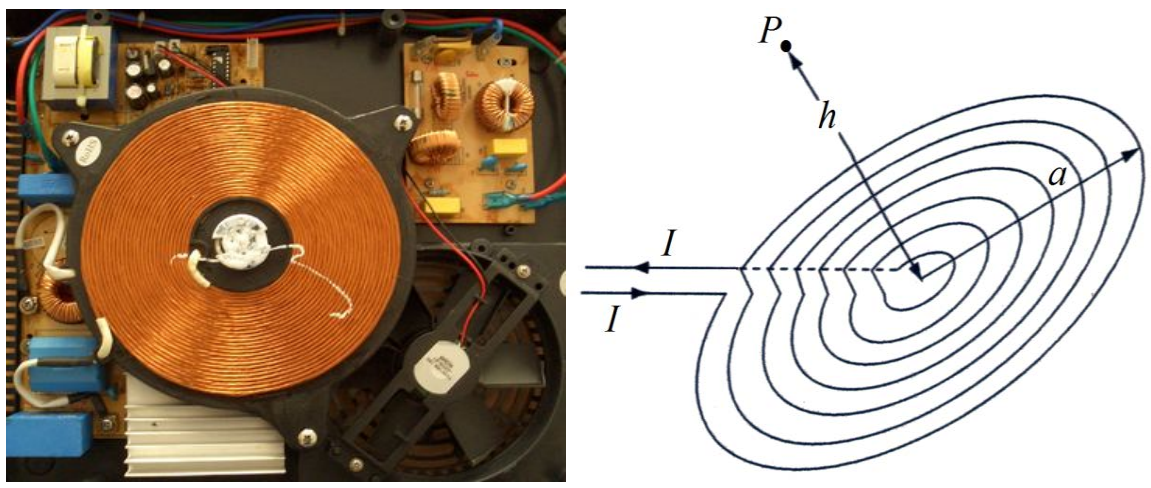

Figure 9. View of an induction stove under vitro-ceramic.

The aforementioned magnetic field passes unobstructed through the ceramic cover (dielectric material) of the cooktop (Figure 10); and penetrates the bowl (pan, pot, frying pan, casserole, etc.) that sits in the cooking zone, creating a circular current in the electrically conductive base of the pan (eddy currents). Due to the presence of these induced currents; and because of the frequency being used, energy is dissipated in the form of heat by the Joule effect, in a high and fast way. In this way, by the principle of magnetic induction, energy is dissipated in the form of heat by the Joule effect. The alternating field is forced to enter the outer layer of the base of the bowl, and since the base of the bowl is made of a conductive material of excellent electrical conductivity, the AC resistance of the material increases as the operating frequency increases, producing an intense heat, making also present the skin effect, by which the intensity of the field can hardly propagate in this type of material and its intensity decreases rapidly.

Likewise, said alternating magnetic field, inside the base of the bowl, also repeatedly magnetizes and demagnetizes the referred material, causing the iron molecules to vibrate between 20,000 to 50,000 times per second, and the friction between them produces additional heat (loss by hysteresis). The superposition of the heat released by the Joule effect, the heat released by the skin effect and the heat due to hysteresis losses are used to cook food.

\section{Liquefied Petroleum Gas (LPG) as Fuel}

Liquefied Petroleum Gas (LPG) is obtained during the refining of crude oil, as one of many by-products. It can also be obtained from the refining of natural gas (in this case another product with different characteristics). It is a mixture of propane $\mathrm{C}_{3} \mathrm{H}_{8}$ and butane $\mathrm{C}_{4} \mathrm{H}_{10}$ - light hydrocarbons, which are organic compounds consisting only of carbon and hydrogen-usually in a $70 \%-30 \%$ or $60 \%$ - $40 \%$ ratio, depending on the target product, whose combustion ratio is indicated in expression (2). LPG evaporates at normal temperatures and pressure, which is why it is distributed or supplied in the classic pressurized balloons or cylinders in a liquid state, hence its liquefiable identity. It is a petroleum derivative with a high calorific value and a higher density than air, used in cooking food, in home heating, as fuel for vehicles and refrigerant, as fuel in furnaces, 


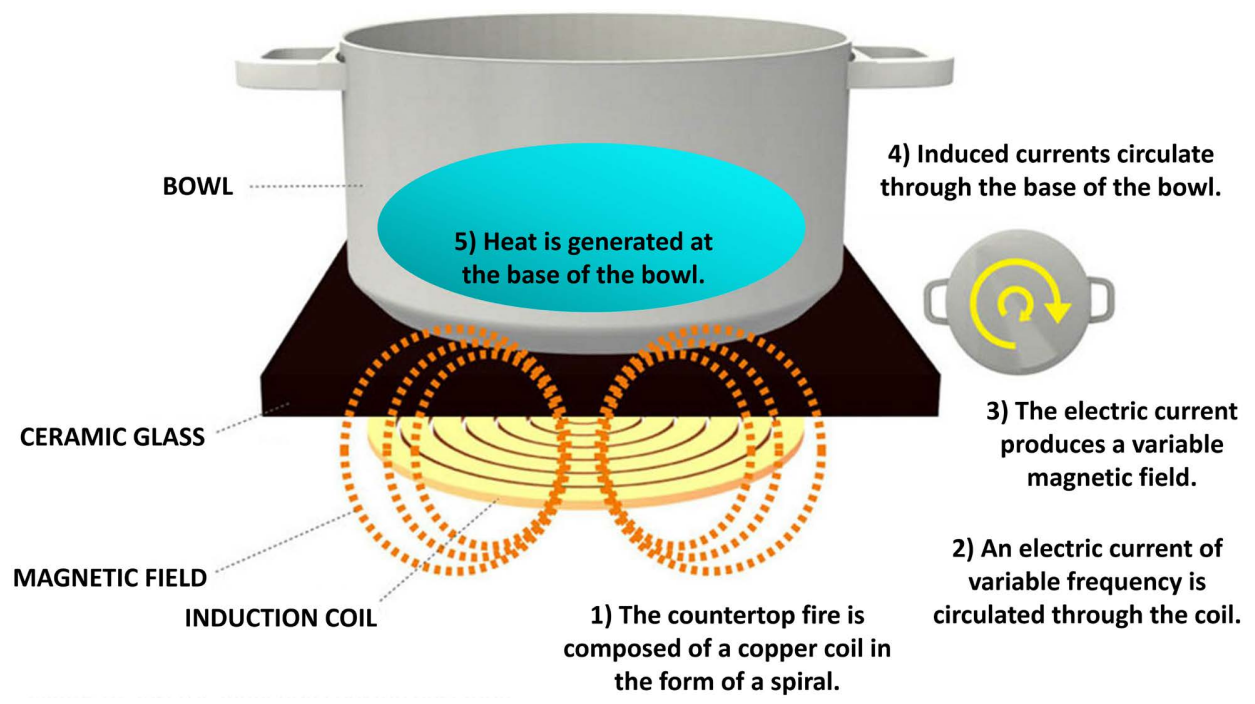

Figure 10. Electric induction cooktop operation.

dryers and boilers in different types of industries, in internal combustion engines and in gas turbines for electric power generation, among others.

$$
2 \mathrm{C}_{3} \mathrm{H}_{8}+2 \mathrm{C}_{4} \mathrm{H}_{10}+23 \mathrm{O}_{2} \rightarrow 14 \mathrm{CO}_{2}+18 \mathrm{H}_{2} \mathrm{O}
$$

The calorific value or heat of combustion is the amount of energy (or heat) released by a given quantity (kilograms, pounds, cubic meters) of substance (fuel) during its complete combustion (oxidation reaction). In other words, the calorific value is the capacity of a fuel to give off heat when it is burning. Hence, assuming a calorific value of $11,500 \mathrm{kcal} / \mathrm{kg}$ for a domestic LPG cylinder $(15 \mathrm{~kg})$, the amount of energy (or heat) capable of being released is as shown in Figure 11.

\section{Cooking Efficiencies}

Taking into consideration the heat transferred to the pan or bowl that remains on the glass ceramic surface, in studies carried out by the United States Department of Energy (DOE), it was determined that the efficiency for different types of cooktops is as shown in Table 2.

In this regard, it is worth noting that the efficiency depends on the size of the pan used compared to the size of the flame/heating surface. Therefore, the efficiency values above are based on an ideal configuration.

Considering the cooking efficiency for each of the sources, it is perfectly possible to decide, by performing a cost analysis, very simple and perfectly comparable, which of them is economically more convenient to the interests of each user. For this purpose, let us suppose that we want to boil 10 liters of water (equivalent to $10 \mathrm{~kg}$ of water) that are at room temperature $\left(25^{\circ} \mathrm{C}\right)$. Thus, the amount of heat and energy required for this purpose is that indicated in (3) and (4) respectively.

$$
\begin{gathered}
Q=m_{\mathrm{H}_{2} \mathrm{O}} C_{\mathrm{H}_{2} \mathrm{O}} \Delta T \Rightarrow Q=10[\mathrm{~kg}] \times 1\left[\frac{\mathrm{kcal}}{\mathrm{kg}^{\circ} \mathrm{C}}\right] \times 75\left[{ }^{\circ} \mathrm{C}\right] \\
Q=750[\mathrm{kcal}]
\end{gathered}
$$



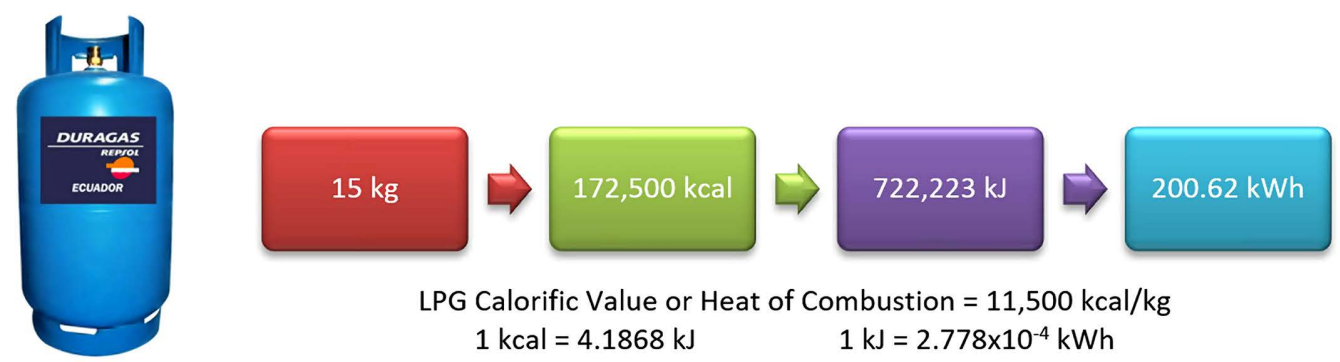

Figure 11. LPG calorific-energy-electricity equivalent.

Table 2. Cooking efficiency for different classes of cooktops [16].

\begin{tabular}{|c|c|c|c|c|}
\hline & \multicolumn{4}{|c|}{ Product Class } \\
\hline & $\begin{array}{c}\text { LPG } \\
\text { cooktop }\end{array}$ & $\begin{array}{c}\text { Electric coil } \\
\text { cooktop }\end{array}$ & $\begin{array}{c}\text { Electric smooth } \\
\text { cooktop }\end{array}$ & $\begin{array}{l}\text { Electric induction } \\
\text { cooktop }\end{array}$ \\
\hline Cooking efficiency & $39.9 \%$ & $73.7 \%$ & $74.2 \%$ & $84.0 \%$ \\
\hline \multicolumn{5}{|c|}{$E=Q[\mathrm{kcal}] \times \frac{4.1868[\mathrm{~kJ}]}{1[\mathrm{kcal}]} \Rightarrow E=750[\mathrm{kcal}] \times \frac{4.1868[\mathrm{~kJ}]}{1[\mathrm{kcal}]}$} \\
\hline
\end{tabular}

From the results obtained in Table 3, it can be clearly seen that it is slightly cheaper to consume $1 \mathrm{kWh}$ of energy through an induction cooktop (12.46 \&USD) than through a conventional electric cooktop; electric smooth cooktop (14.11 \&USD), electric coil cooktop (14.20 \&USD) and through an LPG cooktop (26.16 \&USD).

\section{The Promising of the Electric Induction Cooktop}

In the most elementary way possible, the term "Induction" is linked or related to the term "Reduction", because with the use of this type of cooktops (Figure 12):

1) The heat of the cooking environment is reduced (making it cooler);

2) Cooking times are reduced (linked to effectiveness); and,

3) Energy consumption is reduced (linked to energy efficiency), thereby hopefully reducing the energy bill.

Because of the nature of the science behind the heating method, induction cooking or heating technology offers significant advantages and slight disadvantages over traditional technologies, which are summarized in Table 4 and detailed below.

\section{PROS}

Higher energy efficiency: all energy is utilized, since only the energy needed to heat the vessel is emitted, not the glass or those areas not covered by the vessel. This higher energy efficiency is present in the reduction of heat transfer losses by radiation to the environment.

Quicker heating: heating is faster and the heat is distributed more evenly. 
Table 3. Cost comparison chart for boiling 10 liters of water.

\begin{tabular}{|c|c|c|c|c|}
\hline & \multicolumn{4}{|c|}{ Product class } \\
\hline & LPG cooktop & Electric coil cooktop & $\begin{array}{l}\text { Electric smooth } \\
\text { cooktop }\end{array}$ & $\begin{array}{c}\text { Electric induction } \\
\text { cooktop }\end{array}$ \\
\hline Unit & $\begin{array}{c}\text { Domestic } \\
\text { LPG cylinder }(15 \mathrm{~kg})\end{array}$ & $1 \mathrm{kWh}$ & $1 \mathrm{kWh}$ & $1 \mathrm{kWh}$ \\
\hline Energy per unit & $722,223 \mathrm{~kJ}$ & $3600 \mathrm{~kJ}$ & $3600 \mathrm{~kJ}$ & $3600 \mathrm{~kJ}$ \\
\hline Energy per unit factoring efficiency & $288,166.98 \mathrm{~kJ}$ & $2653.20 \mathrm{~kJ}$ & $2671.20 \mathrm{~kJ}$ & $3024.00 \mathrm{~kJ}$ \\
\hline Units for boiling 10 liters of water & $\begin{array}{l}0.0109 \text { domestic } \\
\text { LPG cilinder }\end{array}$ & $1.1835 \mathrm{kWh}$ & $1.1755 \mathrm{kWh}$ & $1.0384 \mathrm{kWh}$ \\
\hline Cost per unit & $\$ 24 \mathrm{USD}^{\mathrm{a}}$ & $12 థ U S D / k W h$ & $12 \pitchfork U S D / k W h$ & $12 \nsubseteq \mathrm{USD} / \mathrm{kWh}$ \\
\hline Cost of boiling 10 liters of water & $26.16 \pitchfork U S D$ & $14.20 \notin U S D$ & $14.11 \pitchfork \mathrm{USD}$ & $12.46 \pitchfork U S D$ \\
\hline
\end{tabular}

${ }^{\mathrm{a}}$ For the analysis it has been considered the price of a domestic LPG cylinder of $15 \mathrm{~kg}$ at $\$ 24.00 \mathrm{USD}$.

Table 4. Summary of the main pros and cons of electric induction cooktops.

\begin{tabular}{|c|c|c|}
\hline PROS & \multicolumn{2}{|c|}{ CONS } \\
\hline Higher energy efficiency & \multicolumn{2}{|c|}{ Exclusive cookware } \\
\hline Quicker heating & \multicolumn{2}{|c|}{ Acquisition costs } \\
\hline Easier cleaning & \multicolumn{2}{|c|}{ Electric supply } \\
\hline Automatic detection of the vessel & \multicolumn{2}{|c|}{ Emissions of EM radiation } \\
\hline Less environmental pollution & \multicolumn{2}{|c|}{ Steep learning curve } \\
\hline Induction & \multicolumn{2}{|c|}{ Reduction } \\
\hline $\begin{array}{l}\text { LESS } \\
\text { TIME }\end{array}$ & $\begin{array}{l}\text { LESS } \\
\text { ENERGY }\end{array}$ & $\begin{array}{l}\text { LESS } \\
\text { COSTS }\end{array}$ \\
\hline
\end{tabular}

Figure 12. Meaning of electric induction cooking technology.

Easier cleaning: the lower cooking surface temperature prevents the combustion of food residues, resulting in easier cleaning.

Automatic detection of the vessel: the electronic system of induction cooktops incorporates the functionality to program the time you want to have it on or automatically detect the existence or not of a container on the cooking surface, and depending on this, turn on or off, avoiding unnecessary energy consumption; and even adapting to the size of the same, as it incorporates modern signal processing techniques to achieve efficient control of power.

Less environmental pollution: by not using fossil fuels for heating, there is no severe impact on the environment.

CONS

Exclusive cookware: can only be used with ferro-magnetic steel or iron uten- 
sils. Consequently, the kitchen utensils have to be adjusted to this reality. These utensils must also have a flat surface as a base.

Acquisition costs: electric induction cooktops are more expensive than any other regular cooktop.

Electricity supply: the failure or inadequate supply of electricity can cause the cooking process to stop.

Emissions of electromagnetic radiation: due to operating with EM fields of variable frequency, which correspond to the non-ionizing region of the EM Spectrum; however, the heating effect produced by induced currents is very low.

Steep learning curve: when changing to an electric induction cooktop, the user will need to quickly change some of his or her cooking habits.

\section{Technology Substitution Program (TSP)}

From the results obtained and the comparisons made between the different types of cooktops, it is evident to conclude that it is convenient to replace these other technologies with electric induction cooktops; for this purpose, a serious Technological Substitution Program should be developed, whose deployment and implementation should be executed as soon as the feasibility of electric generation exists. For the TSP to be successful, it must comply with the characteristics detailed below and shown in Figure 13.

Specific: The clearer and more detailed the objective is, the easier it will be to establish actions to achieve it, clearly defining to what and with which sectors the implementation of the PST will start.

Measurable: An objective must be measurable through indicators that will allow us to know the level of compliance. Peter Drucker said: "what cannot be measured cannot be controlled, what cannot be controlled cannot be managed and what cannot be managed cannot be improved."

Attainable: Objectives must be reasonable; the target universe and its limits must be defined in a responsible manner.

Relevant: In addition to being attainable, objectives must be relevant, i.e., they must be important for development. A relevant objective will be aligned to the general objectives. For example: economic savings for a given country and for consumers, incentive for producing companies, generation of jobs, and reduction of greenhouse gas emissions among others.
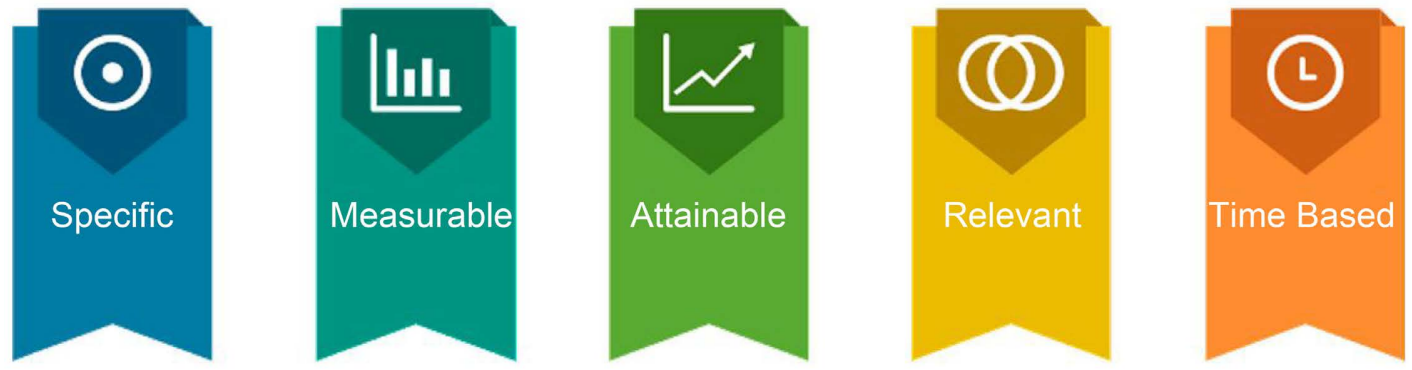

Figure 13. SMART characteristics of the technology substitution program. 
Time based: This is precisely why SMART objectives emphasize the importance of delimiting the achievement of objectives within a specific timeframe. A valid objective must be delimited in a time frame in which it has to be achieved because it helps us to have a limit on the horizon and not to procrastinate. It must be duly accompanied by a strict execution schedule.

\section{Motivations for TSP's Implementation}

Hand in hand and correlated with the implementation of this technological program, is undoubtedly the technical, economic and financial impact on the electric power distribution companies in the country that decide to continue with the deployment of electric induction technologies in cooking, because the operation of the same, will generate a severe increase in the demand for power and energy; Therefore, corrective measures must be foreseen in a planned manner in the electrical distribution and transmission networks, corrective measures that imply improvements and repowering of the conductors of the different circuits, division and increase of those, improvement of the electrical service connections; without leaving aside, of course, the compensation of the reactive energy that these induction plates will demand; which will be necessary, if its compensation is not considered at the moment of its manufacture or assembly. The main motivations for the implementation of the TSP are detailed below.

Obtaining energy savings: Through efficient cooking and the use of appropriate appliances, there would be a reduction in radiant heat and direct and indirect economic savings.

Contributing to energy security: Through improvements to the national electricity system, there would be an increase in the reliability of energy infrastructures, increasing the capacity to meet current and future demand.

Contributing to energy equity: Through energy security and the deployment of electric grids, energy supply would be accessible and affordable for the entire population.

Contributing to the mitigation of environmental impact: Through the technological replacement of cooktops, linked to energy efficiency and savings, there would be a reduction of pollutants and GHG emissions, improvement in social and environmental conscience, reduction of deforestation and its global consequences, as well as a suitable environment for the development of sustainable energy systems.

\section{Energy Use and Payback Period}

In order to be able to adequately prepare Table 5 , and thus determine the payback period corresponding to the substitution of the cooking technology; but, related only to the additional value that would have to be paid for it versus the economic savings in energy costs, it is necessary to consider that, based on Technology Brief R06 [17], prepared jointly by the International Energy Agency (IEA) \& Energy Technology System Analysis Programme (ETSAP), the Annual Energy 
Table 5. Annual energy consumption and payback period of cooktop technologies.

\begin{tabular}{lcccc}
\hline & \multicolumn{3}{c}{ Product class } \\
\cline { 2 - 5 } & $\begin{array}{c}\text { LPG } \\
\text { cooktop }\end{array}$ & $\begin{array}{c}\text { Electric } \\
\text { coil cooktop }\end{array}$ & $\begin{array}{c}\text { Electric smooth } \\
\text { cooktop }\end{array}$ & $\begin{array}{c}\text { Electric induction } \\
\text { cooktop }\end{array}$ \\
\hline Cooking efficiency & $39.9 \%$ & $73.7 \%$ & $74.7 \%$ & $84.0 \%$ \\
Annual energy consumption (AEC) & $330 \mathrm{kWh} / \mathrm{yr}$ & $240 \mathrm{kWh} / \mathrm{yr}$ & $250 \mathrm{kWh} / \mathrm{yr}$ & $190 \mathrm{kWh} / \mathrm{yr}$ \\
Cooking energy & $131.67 \mathrm{kWh} / \mathrm{yr}$ & $176.88 \mathrm{kWh} / \mathrm{yr}$ & $186.75 \mathrm{kWh} / \mathrm{yr}$ & $159.60 \mathrm{kWh} / \mathrm{yr}$ \\
Energy annual cost & $\$ 39.48 \mathrm{USD} / \mathrm{yr}$ & $\$ 28.80 \mathrm{USD} / \mathrm{yr}$ & $\$ 30.00 \mathrm{USD} / \mathrm{yr}$ & $\$ 22.80 \mathrm{USD} / \mathrm{yr}$ \\
Energy savings by technology substitution & $140 \mathrm{kWh} / \mathrm{yr}$ & $50 \mathrm{kWh} / \mathrm{yr}$ & $60 \mathrm{kWh} / \mathrm{yr}$ & $0 \mathrm{kWh} / \mathrm{yr}$ \\
Cost of energy savings by technology substitution & $\$ 16.75 \mathrm{USD} / \mathrm{yr}$ & $\$ 6.00 \mathrm{USD} / \mathrm{yr}$ & $\$ 7.20 \mathrm{USD} / \mathrm{yr}$ & $\$ 0 \mathrm{USD} / \mathrm{yr}$ \\
Payback period by technology substitution & $23.88 \mathrm{yr} \mathrm{a}^{\mathrm{a}}$ & $50.00 \mathrm{yr}$ & $41.67 \mathrm{yr} \mathrm{b}^{\mathrm{b}}$ &
\end{tabular}

A residential market study carried out particularly on cooktops concluded that induction technology. ${ }^{a}$ to be at least $\$ 400$ USD more expensive than comparable LPG cooktop products. ${ }^{\text {b }}$ to be at least $\$ 300$ USD more expensive than comparable electric cooktop products.

Consumption (AEC) for an electric coil cooktop and an electric smooth cooktop is $240 \mathrm{kWh}$ and $250 \mathrm{kWh}$, respectively; likewise, for an electric induction cooktop and a domestic LPG cooktop it is $190 \mathrm{kWh}$ and $330 \mathrm{kWh}$, in that order.

Depending on the country or region to which this study is being extrapolated, these reference values may vary, and will undoubtedly be a function of usage and/or good or bad cooking habits. Additionally, the energy costs associated with this activity will be determined based on the information contained in Table 3 .

The following has been considered in this study:

1) For the electric coil cooktop, the baseline efficiency applies to a cooktop composed of four radiant coil elements. This cooktop was assumed to consist of two 6-inch elements and two 8-inch elements. The electrical input ratings of the 6 -inch and 8-inch elements were assumed to be 1250 watts and 2100 watts, respectively;

2) For electric smooth cooktops, the baseline efficiency applies to a cooktop composed of four solid disk elements. This cooktop was assumed to consist of two 6-inch elements and two 8-inch elements. The electrical input ratings of the 6-inch and 8-inch elements were assumed to be 1500 watts and 2000 watts, respectively;

3) For the LPG cooktop was assumed to consist of four conventional (open) gas burners. Each burner was rated at $9000 \mathrm{Btu} / \mathrm{h}$;

4) All electric and gas cooktops are equipped with an electronic ignition device, so that the energy factor is equal to the cooking efficiency;

5) The technical lifetime for all cooktops is 19 years;

6) The payback period refers to the time when the energy savings due to efficient induction cooking have paid for the additional cost of the induction unit.

\section{Discussion}

With the application of the TSP, energy savings will be achieved that go hand in 
hand with the reduction of pollutants, but regardless of this, and despite having the latest or best technology in electric induction cooktop in our hands, the small savings in the energy bill will not compensate the additional costs of acquisition and installation of those, the short-term savings should not be confused with the overall reduction of costs.

To promote energy efficiency, not only should environmentally responsible norms or standards be established and a regulatory framework developed, but also consumer awareness and education are crucial issues.

To improve energy access at local, regional and global levels, new energy technologies must be developed, new infrastructure must be built and obsolete infrastructure must be replaced. Large investments are necessary; therefore, market conditions capable of attracting long-term investments must be supported.

For the private sector to invest in environmentally responsible and energy-efficient technologies, intellectual property rights must be strongly protected.

With the implementation and deployment of the TSP, and if any type of energy subsidy is considered, as Ecuador once did in its time, it should be analyzed with care, with the purpose of causing the least possible social impact, remembering that the balance of economic, financial, social and environmental returns must coexist.

It is worth pointing out that with this TSP, the use of domestic gas will not disappear, since the ovens-an integral part of a "stove" as a whole-will remain to be operated with LPG or electricity but not with magnetic induction, at least for the time being.

Even if there is an oversupply of energy, in order to simultaneously improve the three dimensions of the energy trilemma: energy security, energy equity and environmental sustainability, there will always be the possibility of failure in the supply of electric service, since no system is invulnerable to atmospheric events, bad maneuvers, lack of coordination or even sabotage. Therefore, it would be necessary to analyze the alternative of considering that electric induction cooktop include gas burners.

Finally, it is important to consider that since this TSP will be focused initially on rural areas, there should be Customer Service Centers (CSC) that have the technical capacity to provide an immediate response for repair or replacement of the cooktop plate, in order to avoid the production of unnecessary electronic waste.

\section{Conclusions}

1) Table 3 clearly shows that, with induction technology, the lowest annual energy consumption is achieved; besides, due to its high cooking efficiency, the amount of energy used for cooking is lowest. Similarly, according to Table 5, the highest value of energy savings is obtained, i.e., $140 \mathrm{kWh} / \mathrm{yr}$, by replacing an LPG cooktop with an electric induction cooktop, not to mention the possible longterm side effects and damage of breathing the combustion products of liquefied 
petroleum gas in homes that do not have exhaust hoods or have a kitchen that is not very well ventilated. In addition, for the user, the induction cooktop represents annual savings of $50 \mathrm{kWh}$ and $\$ 6.00 \mathrm{USD}, 60 \mathrm{kWh}$ and $\$ 7.20 \mathrm{USD}$; and $140 \mathrm{kWh}$ with $\$ 16.75$ USD for replacing the electric coil cooktop, electric smooth cooktop and LPG cooktop, respectively. However, this implies a simple payback period of $50,41.67$ and 23.88 years, respectively, which represents a factor between 1.26 and 2.63 times of the expected lifetime of these cooktops (19 years). Therefore, at this point, despite its other advantages of controllability and safety, it can be concluded that the electric induction cooktop does not offer a cost-effective method of energy savings.

2) Energy use for cooking-whether gas or electricity-is a very small percentage of typical household energy consumption (about 5\%), so there are more important places or activities to put effort in relation to savings. However, any energy savings, above all, a relevant reduction of GHG emissions, will contribute greatly to sustainability management.

3) Gas is a primary energy source, while electricity is a secondary energy source; this is because coal or gas is used to generate electricity. By the time electricity reaches households, much energy has already been lost in the generation, transmission and distribution stages. Therefore, if these losses and efficiency are taken into account, both sources (gas or electricity) could be equal and it is personal preference or economic value that should guide the decision, without losing sight of the existence of mandatory nature of their use as a state policy.

4) The community is concerned about electromagnetic emissions, which are lower in electric glass-ceramic systems than in induction ones; however, the latter are much more efficient than the former. Thus, the operating time of the equipment (and thus the duration of exposure to such emissions) is much shorter in induction stoves. For now, the available data suggest that, if there are non-thermal effects of non-ionizing radiation absorption on human health, such effects are not so profound as to be easily discernible. In fact, according to expression (1), the magnetic flux density by the exponent to which it is raised, decreases very rapidly with distance. So, if exposure occurs, its effects will be minimal and would not pose a risk, except to users with active implants, and more specifically, to people implanted with pacemakers.

5) The Technological Substitution Program (TSP) together with efficient cooking must be seen as the means to guarantee inclusive decarbonization, which does not leave any community behind, becoming an essential part of humanizing the energy transition.

6) Cost, in fact, is the greatest barrier to the adoption of induction technology [18]. In Table 5, the payback period by technology substitution was determined; however, in these calculations, the cost related to the acquisition of inductioncompatible cookware was not considered. This could represent several hundred dollars, which would be added to the induction technology premium, depending on the culinary needs of the user, of course.

7) The deployment of induction cooktops will undoubtedly lead to the rein- 
forcement of energy infrastructures, and if to this is added the diversification of the energy mix through renewable sources, then the countries that adopt this study will be closer to achieving a sustainable energy system, and will be guaranteed to obtain a balanced score in the general index of the Energy Trilemma.

\section{Data Availability Statement}

The data used in this study can be obtained by contacting the corresponding author.

\section{Acknowledgements}

The author wishes to sincerely thank Valeria Carolina Tama Guerra, MSEE and Andrea Stephanie Tama Guerra, BSEE for their reviews and critical comments.

\section{Conflicts of Interest}

The author declares no conflicts of interest regarding the publication of this paper.

\section{References}

[1] Ghenai, C. (2012) Life Cycle Analysis of Wind Turbine. In: Ghenai, P.C., Ed., Sustainable Development-Energy, Engineering and Technologies-Manufacturing and Environment, IntechOpen, London, 19-32.

[2] World Energy Council (2021) World Energy Issues Monitor. World Energy Council, London.

[3] National Oceanic and Atmospheric Administration (2021, June 7) Carbon Dioxide Peaks near 420 Parts per Million at Mauna Loa Observatory. https://research.noaa.gov/article/ArtMID/587/ArticleID/2764/Coronavirus-respons e-barely-slows-rising-carbon-dioxide

[4] Scripps Institution of Oceanography (n.d.) The Keeling Curve. University of California, San Diego. https://keelingcurve.ucsd.edu/

[5] Global Monitoring Laboratory (2022, January 5) Trends in Atmospheric Carbon Dioxide. https://gml.noaa.gov/ccgg/trends/

[6] Friedlingstein, P., Jones, M.W., O’Sullivan, M., Andrew, R.M., Bakker, D.C.E., Hauck, J., Le Quéré, C., Peters, G.P., Peters, W., Pongratz, J., Sitch, S., Canadell, J.G., Ciais, P., Jackson, R.B., Alin, S.R., Anthoni, P., Bates, N.R. and Becker, M. (2022) Global Carbon Budget 2021. Global Carbon Project, Canberra. https://doi.org/10.5194/essd-2021-386

[7] Global Carbon Project (2021, November 4) Global Carbon Budget 2021. https://www.globalcarbonproject.org/carbonbudget/21/files/GCP_CarbonBudget_2 021.pdf

[8] World Energy Council (2021) World Energy Trilemma Index 2021. World Energy Council 2021, London.

[9] United Nations Educational, Scientific and Cultural Organization (n.d.) What Is Education for Sustainable Development? https://en.unesco.org/themes/education-sustainable-development/what-is-esd

[10] Stockholm Resilience Centre, Stockholm University (2016, June 14) Sustainable Development Goals: The SDGs Wedding Cake. Stockholm Resilience Centre. 
https://www.stockholmresilience.org/research/research-news/2016-06-14-the-sdgswedding-cake.html

[11] Mayhew, N. (2019) The IAEA and Climate Change: Adaptation, Monitoring and Mitigation. International Atomic Energy Agency.

https://www.iaea.org/newscenter/news/the-iaea-and-climate-change-adaptation-mo nitoring-and-mitigation

[12] Tama, A. (2013) Cocina de Inducción versus Cocina a Gas (GLP). Revista Técnica del Colegio Regional de Ingenieros Eléctricos y Electrónicos del Litoral, 31, 8-14.

[13] Tama, A. (2016) Fundamentos de Electromagnetismo. Primera Edition, Bubok Publishing S.L., Guayaquil, Guayas, 444-494.

[14] Ida, N. (2015) Engineering Electromagnetics. 3rd Edition, Springer International Publishing, Cham, 383-426. https://doi.org/10.1007/978-3-319-07806-9

[15] Uechi, H. and Uechi, S.T. (2020) Thermoelectric Energy Conversion of a Drinking Bird by Disk-Magnet Electromagnetic Induction. World Journal of Engineering and Technology, 8, 204-216. https://doi.org/10.4236/wjet.2020.82017

[16] Lawrence Berkeley National Laboratory (1998) Technical Support Document for Residential Cooking. U.S. Department of Energy (DOE), Berkeley.

[17] Griffin, M., Ramsson, T. and Gibson, G. (2012, June) Cooking Appliances. Energy Technology Systems Analysis Program, International Energy Agency, Paris.

https://iea-etsap.org/E-TechDS/PDF/R06_Cooking_FINAL_GSOK.pdf

[18] Laureti, L., Rogges, M.G.L. and Costantiello, A. (2018) Evaluation of Economic, Social Effects of Renewable Energy Technologies. Journal of Environmental Protection, 9, 1143-1154. https://doi.org/10.4236/jep.2018.911071 


\section{Abbreviations}

$\begin{array}{ll}\text { AEC } & \text { Annual Energy Consumption } \\ \text { CEC } & \text { Customer Service Centers } \\ \text { DOE } & \text { United States Department of Energy } \\ \text { EM } & \text { Electromagnetics } \\ \text { ETSAP } & \text { Energy Technology System Analysis Programme } \\ \text { GHG } & \text { Greenhouse Gas } \\ \text { IAEA } & \text { International Atomic Energy Agency } \\ \text { IEA } & \text { International Energy Agency } \\ \text { LPG } & \text { Liquefied Petroleum Gas } \\ \text { NOAA } & \text { National Oceanic and Atmospheric Administration } \\ \text { PPM } & \text { Parts Per Million } \\ \text { SD } & \text { Sustainable Development } \\ \text { SDG } & \text { Sustainable Development Goals } \\ \text { TSP } & \text { Technical Substitution Program } \\ \text { WEC } & \text { World Energy Council }\end{array}$

